J. Lake Sci. (湖泊科学), 2005, 17(2): 143-150

ISSN 1003 -5427; E-mail: jlakes@ niglas. ac.cn

Copyright 2005 by Journal of Lake Sciences

\title{
太湖近代沉积物中重金属元素的累积”
}

\author{
朱广伟 ${ }^{1}$, 秦伯强 ${ }^{1}$, 高 光 $^{1}$, 罗潋葱 ${ }^{1}$, 王文敏 ${ }^{2}$ \\ ( 1 : 中国科学院南京地理与湖泊研究所,南京 210008) \\ ( 2 : 江西农业大学理学院,南昌 330045 )
}

摘 要: 利用 ${ }^{210} \mathrm{~Pb} 、{ }^{137} \mathrm{Cs}$ 定年技术, 对来自太湖不同生态和沉积特征的三个湖区的沉积物柱状样品进行了定年, 用 ICP AES 分析了沉积物中重金属等元素的含量,分析了太湖沉积物中重金属的累积特征及其成因. 污染较重、蓝藻水华暴发 频繁的梅梁湾沉积物中的重金属含量在近 25 年来逐年增加; 太湖上游风浪较大的夹浦湖区表层 $10 \mathrm{~cm}$ 沉积速率大、粒度 粗,除表层 $1 \mathrm{~cm}$ 外, $1-10 \mathrm{~cm}$ 沉积物中各种重金属含量都较低,且层间变化剧烈;下游湖区正逐渐草型化的胥口湾除表层 $3 \mathrm{~cm}$ 外,沉积物中重金属的含量自底层向表层大致呈不断下降的趋势. 研究表明,不同年代的太湖沉积物中重金属含量差 异很大, 明显大于不同湖区间沉积物重金属平均含量间的差异. 水动力作用引起的沉积物粒度分异很可能是影响沉积物 中重金属积累的一个重要因素. 总体上太湖沉积物中重金属的污染比较轻微, 但已经有一定程度的 Cd 污染, 梅梁湾沉积 物中自上世纪 70 年代开始明显积累 $\mathrm{Cd}$,其他重金属元素的积累也逐渐增加,值得关注.

关键词:沉积物; 重金属; 水动力; 污染源; 太湖; 浅水湖泊

\section{Accumulation Characteristics of Heavy Metals in the Sediments of Lake Taihu, China}

\author{
ZHU Guangwei $^{1}$, QIN Boqiang ${ }^{1}$, GAO Guang ${ }^{1}$, LUO Liancong ${ }^{1} \&$ WANG Wenmin ${ }^{2}$ \\ ( 1 : Nanjing Institute of Geography and Limnology, Chinese Academy of Sciences, Nanjing 210008, P. R. China) \\ (2 : Jiangxi Agricultural University, Nanchang 330045, P. R. China)
}

\begin{abstract}
Accumulation characteristics of heavy metals in sediment cores from three lake areas of Lake Taihu, a typical large-shallow freshwater lake in China, were studied with ${ }^{210} \mathrm{~Pb}$ and ${ }^{137} \mathrm{Cs}$ isotope dating method. Meiliang Bay of Lake Taihu, a eutrophic shallow bay with a deepest depth of less than $2.6 \mathrm{~m}$, occurred cyanobacterium algae-bloom every year and received large amount of municipal sewage and industrial wastewater since the middle of $1980 \mathrm{~s}$, has a significant increas trend of the contents of Cd, Cr, $\mathrm{Cu}, \mathrm{Ni}, \mathrm{Pb}$, and $\mathrm{Zn}$ in sediment since the recent 25 years. Jiapu District of Lake Taihu, located in the upper reach of Lake Taihu with a disturbed and yellow water, have a significantly low but also drastically varied contents of heavy metals in sediments of 1 $10 \mathrm{~cm}$ layer from top to bottom, and a largest sedimentation rate and a largest median particle size at the same layer. Xukou Bay of Lake Taihu, a shallow bay located in the lower reaches of Lake Taihu and gradually become macrophyte-dominant lake in recent 10 years, have a decreasing trend of the contents of heavy metals in sediment from bottom to top except the top $3 \mathrm{~cm}$ layer, which the contents of heavy metals abruptly increased. The difference of the content of heavy metals among different sediment time was significant higher than the difference of the mean value of the contents of heavy metals among different sediment cores, which resulted in the different evaluating conclusion of heavy metal pollution in different periods. For example, in the middle of 1980s, it was concluded that no Cd pollution of sediment in Meiliang Bay but there was Cd pollution of sediment in Xukou Bay. However, in 2000, it was concluded that Meiliang Bay was the most serious Cd polluted area in Lake Taihu by sediment quality evaluation. Hydrodynamics also could drastically affect the heavy metals sediment in the large-shallow and frequently wind-induced wave disturbing lake by dynamical size differentiation.
\end{abstract}

Keywords: Sediment; heavy metals; hydrodynamics; pollution sources; Lake Taihu; shallow lake

关于太湖沉积物中重金属的污染和分布状况,最早、最全面的调查是 $1980-1981$ 年无锡市环境保护局 和中国科学院南京地理与湖泊研究所组织的太湖环境质量调查研究 ${ }^{[1]}$. 该调查从流域角度对土壤、工业污 
染源、非点源污染、河流、湖泊水质、沉积物的重金属、营养盐等污染状况进行了全面的调查, 着重分析了沉 积物中丞、砷、铬的污染状况. 结果表明部分河口及梅梁湾地区有轻微的重金属污染, $99 \%$ 的湖区为清洁和 较清洁湖区 ${ }^{[1]}, 1988$ 年中国科学院南京地理与湖泊研究所再次对太湖沉积物的重金属污染进行了调查 ${ }^{[2]}$, 确定了无锡、苏州和长兴沿岸是重金属的主要污染区. 2000 年前后,太湖沉积物中的重金属污染再次得到 关注,袁旭音等对比了湖岸土壤与表层沉积物重金属含量间的关系 ${ }^{[3]}$; 范成新等人评价了太湖西岸宜溧河 流域主要河流沉积物重金属污染现 ${ }^{[4]}$; 戴秀丽等人对梅梁湾、竺山湾、贡山湾等太湖北部湖区的表层沉 积物重金属污染状况进行了评价 ${ }^{[5]}$; 王海等对太湖表层沉积物中重金属的生物有效性进行了研究 ${ }^{[6]}$; 张于 平、石浚哲等人也在对太湖表层沉积物样品的分析结果基础上评价了太湖的重金属污染 ${ }^{[7,8]}$. 这些研究基 本都反映出太湖的重金属污染呈现北部湖区重于其他湖区, 河口区重于非河口区. 然而, 这些研究都是进 行表层沉积物的污染现状调查, 并没有对沉积物记录的重金属污染历史进行研究. 另外, 由于太湖的出人 河道众多, 面积大, 软性底泥占全湖面积的 $69.83 \%{ }^{[9]}$, 因而大多数调查缺乏对太湖整体性污染状况的认 识 ${ }^{[3-5]}$. 刘恩峰等对太湖马迹山南部一个点位沉积物岩心的年代分析及重金属含量测定, 反映出近百年来 该湖区重金属累积特征 ${ }^{[10]}$, 但对于太湖重污染湖区、上游湖区、及下游草型湖区等典型湖区的情况并不清 楚. 本文通过 ${ }^{210} \mathrm{~Pb} 、{ }^{137} \mathrm{Cs}$ 沉积物年代学测定, 分析了太湖不同湖区的沉积物中重金属的污染状况及其积累 规律, 对认识太湖地区人类活动与湖泊响应之间的关系提供依据.

\section{1 材料与方法}

\section{1 样品的采集}

西部、西南部、西北部为太湖的主要人流区, 小梅口附近人流的苕溪、大浦口附近人流的宜溧河每年的 人流水量占太湖年人湖水量的 $90 \%$ 以上. 东部为太湖的主要出水区, 与东太湖相连的太浦河是太湖的主要 出口, 其次是与贡山湾相连的望虞河及与胥口湾相连的胥江. 梅梁湾、竺山湾是太湖污水的主要人流区, 直 湖港、太滆运河、漕桥港、太滆南运河是污水的主要人湖河道, 这几条河人湖的磷占主要人湖河流输人量的 $75 \%{ }^{[11]}$. 水质和生态类型上, 太湖具有明显的空间异质性, 这也是浅水湖泊所共有的一个特征 ${ }^{[12]}$. 水质上 梅梁湾水体悬浮物浓度高于湖心区, 湖心区高于东太湖 ${ }^{[13]}$. 生态特征上北部太湖的梅梁湾、竺山湾及大浦

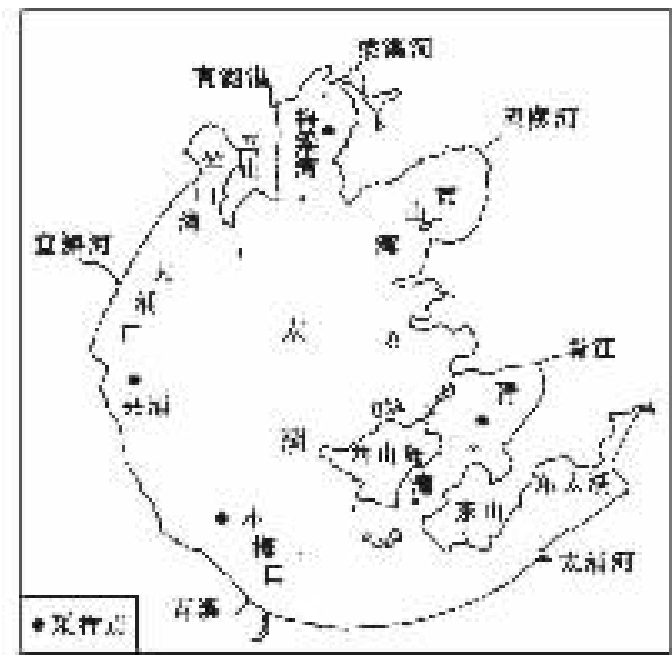

图 1 采样点分布图

Fig. 1 Map of the sampling site 口一带频繁暴发大面积的蓝藻水华, 呈现藻型湖泊特 征 ${ }^{[14]}$;东太湖、胥口湾的部分区域、贡山湾的部分区域 等东部湖区则呈现出草型湖泊的特征, 部分湖区甚至 出现沼泽化的迹象 ${ }^{[15,16]}$; 西南太湖受上游来水及沉积 物特征的影响, 除沿岸带零星分布芦苇等挺水植物 外, 主要湖面的水草和藻类分布都不多, 水质多呈黄 浑状态.

本研究考虑到污染状况和水质、生态类型因素, 2002 年 5 月 $11-25$ 日在太湖北部的梅梁湾 $\left(31.48381^{\circ} \mathrm{N}, 120.20176^{\circ} \mathrm{E}\right) 、$ 西部的夹浦 $\left(31.20686^{\circ} \mathrm{N}\right.$, $\left.119.95415^{\circ} \mathrm{E}\right)$ 、东部的胥湖湾 $\left(31.16069^{\circ} \mathrm{N}\right.$, $120.39750^{\circ} \mathrm{E}$ ) 采集沉积物柱状样品进行研究 (图 1). 采样期间梅梁湾采样点大面积暴发蓝藻水华,夹浦采 样点风浪大, 水质黄浑, 有明显的泥沙, 胥口湾采样点 分布着成片的马来眼子菜等水草,水质清澈. 用手持 式沉积物泥芯采样器采集沉积物柱状样, 取柱状样的 表层约 $30 \mathrm{~cm}$ 进行年代学研究. 用于粒度测定的小梅 口 $\left(31.05083^{\circ} \mathrm{N}, 120.06067^{\circ} \mathrm{E}\right)$ 沉积物柱状样品于 2001 年 6 月采集 (图 1). 采集表层 $26 \mathrm{~cm}$ 的沉积物样品, 自上而下每 $2 \mathrm{~cm}$ 分为一层, 共分 13 层, 用于沉积 物粒度分析. 


\section{2 沉积物年代测定}

按照自上而下每 $1 \mathrm{~cm}$ 一个样品进行分层, 称取沉积物的鲜重, 自然风干, 再称取每层沉积物的干重, 以 获得层沉积物的含水率和干重. 样品研磨后, 对表层 $30 \mathrm{~cm}$ 的样品, 称取约 $5 \mathrm{~g}$ 样品用 ORTEC 高纯锗低本底 $\gamma$ 能谱仪 ${ }^{210} \mathrm{~Pb} 、{ }^{137} \mathrm{Cs}$ 含量测定, 来确定沉积物的沉积年代. 梅梁湾、胥口湾的沉积物柱样的年代测定的有效 深度为 $28 \mathrm{~cm}$, 夹浦为 $25 \mathrm{~cm}$.

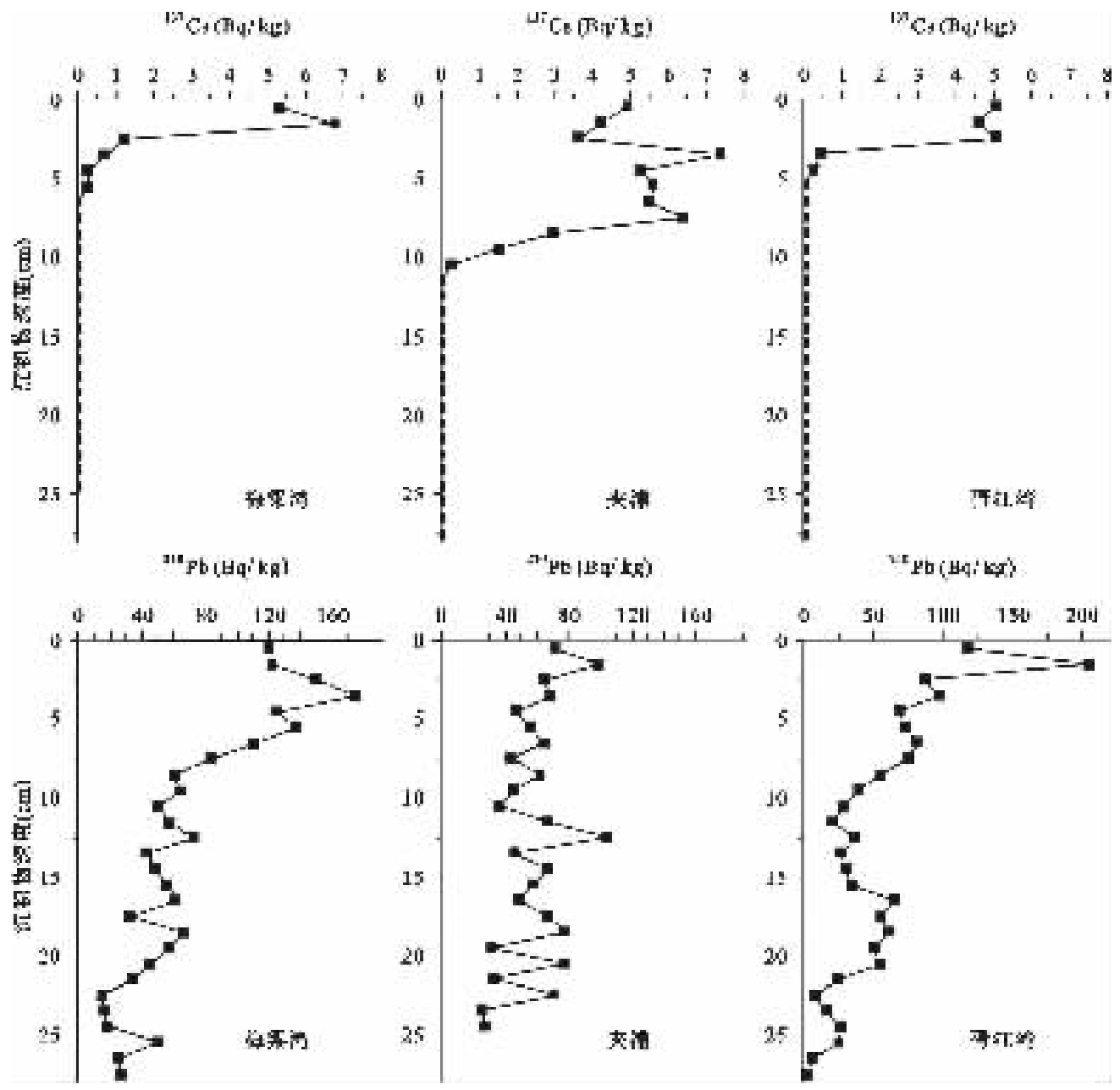

图 2 沉积物中 ${ }^{137} \mathrm{Cs} 、{ }^{210} \mathrm{~Pb}$ 含量的垂向分布

Fig. 2 Vertical distribution of ${ }^{137} \mathrm{Cs}$ and ${ }^{210} \mathrm{~Pb}$ in the sediment cores

\section{3 样品分析}

样品风干、研磨、 $105^{\circ} \mathrm{C}$ 烘干后, $550^{\circ} \mathrm{C}$ 灼烧 $5 \mathrm{~h}$, 测定烧失量 ( LOI), 用以估算有机质含量. 灼烧后的样品 用 $35 \mathrm{ml} 1 \mathrm{~mol} / \mathrm{L}$ 的优级纯盐酸溶液振荡提取 $16 \mathrm{~h}$ (振幅 $5 \mathrm{~cm}$, 频率为 250 次 $/ \mathrm{min}$ ). Leeman Labs Profile ICP-AES 测定提取液中 $\mathrm{Al} 、 \mathrm{Ca} 、 \mathrm{Fe} 、 \mathrm{Mn} 、 \mathrm{Cd} 、 \mathrm{Cr} 、 \mathrm{Cu} 、 \mathrm{Ni} 、 \mathrm{~Pb} 、 \mathrm{Zn}$ 含量. 其中 $\mathrm{Al} 、 \mathrm{Ca} 、 \mathrm{Fe} 、 \mathrm{Mn}$ 主要反映沉积物的基 本性质, $\mathrm{Cd} 、 \mathrm{Cr} 、 \mathrm{Cu} 、 \mathrm{Ni} 、 \mathrm{~Pb} 、 \mathrm{Zn}$ 为重金属元素. 分析 GSD-9、GSD-12 地球化学标准样, 用以了解提取的效率及 重现性. 沉积物粒度分析用 Malvern Masterisizer 2000 激光粒度仪测定. 


\section{2 分析结果}

\section{1 沉积物的年代测定}

三个沉积物柱的 ${ }^{137} \mathrm{Cs}$ 和 ${ }^{210} \mathrm{~Pb}$ 测定结果见图 2.

除夹浦沉积物柱中的 ${ }^{210} \mathrm{~Pb}$ 垂向变化规律较乱外,其余沉积物的 ${ }^{137} \mathrm{Cs}$ 和 ${ }^{210} \mathrm{~Pb}$ 较为稳定. 夹浦沉积物柱 中的 ${ }^{210} \mathrm{~Pb}$ 垂向变化规律不好的原因很容易被归结为是沉积后的扰动作用引起,包括水动力扰动和人类活 动扰动. 作为一个大型的浅水湖泊, 太湖的水动力作用对沉积物的扰动比较大. 据观测, 在风速 $6.5 \mathrm{~m} / \mathrm{s}$ 以 上时, 风浪可以引起湖水中悬浮物浓度提高数倍甚至数十倍 ${ }^{[17]}$, 而风速在 $6.5 \mathrm{~m} / \mathrm{s}$ 以上的情况在太湖是相 当常见 ${ }^{1}$, 频繁的风浪扰动使得太湖的表层沉积物反复地发生沉积、再悬浮、再沉积,这给湖泊的沉积年代 确定带来了困难. 就风浪扰动强度而言, 夹浦由于在湖面开阔的大太湖, 所以受风浪扰动的强度要大于其 余两个样点. 另外,太湖的风生流的流速一般在 $2 \mathrm{~cm} / \mathrm{s}$ 以上 ( 风速在 $3 \mathrm{~m} / \mathrm{s}$ 以上) ${ }^{[18]}$, 尽管这样的流速对于 沉积物的再悬浮影响较小,对于悬浮物的迁移作用还是相当明显的.

比较三个采样点湖流特征, 胥江湾和梅梁湾由于都处于湖湾中, 而太湖风生流主要是在大太湖区形成 一个环流 ${ }^{[19]}$, 因此夹浦受湖流等水动力的扰动频率和强度都要大于其余两点. 太湖的捕鱼、捉虾、淘螺蛳 等人类活动频繁. 这些沉积后的扰动可能会引起沉积物 ${ }^{210} \mathrm{~Pb}$ 垂向分布的无规律. 然而,水动力扰动引起夹 浦沉积物中 ${ }^{210} \mathrm{~Pb}$ 沉积层序扰动的解释似乎还不能成立. 因为, 就人类活动的强度而言, 梅梁湾、胥江湾地区 显然要大于夹浦一带,而梅梁湾和胥江湾的 ${ }^{210} \mathrm{~Pb}$ 沉积层序尚可. 另外, 就夹浦沉积物柱本身而言, ${ }^{137} \mathrm{Cs}$ 的 记录情况也比较好, 并未显示出表层明显受到扰动的特征, 只是 ${ }^{210} \mathrm{~Pb}$ 的沉积规律混乱. 因此,沉积后扰动可 能不完全是影响夹浦沉积物柱中 ${ }^{210} \mathrm{~Pb}$ 沉积混乱的原因, 也许是沉积物在沉积过程中发生了选择性沉积, 或 者是流域输人变化等沉积本身的原因造成的.

\section{2 沉积物中元素的酸提取效率}

$1 \mathrm{~mol} / \mathrm{L}$ 的盐酸溶液提取并不能将沉积物中的金属元素全部得到提取,但是能够将其中的大部分生物 有效态提取出来,类似的提取在土壤重金属研究和沉积物磷的分析中都有应用 ${ }^{[20,21]}$. 不同的元素,盐酸提 取的效率不同,不同性质的沉积物,盐酸提取的效率也不同. GSD-9、GSD-12 水系沉积物地球化学标准样中 各元素的盐酸可提取部分的含量 $\left(\mathrm{E}_{\mathrm{HCl}}\right)$ 及标准含量 $\left(\mathrm{E}_{\mathrm{Std}}\right)$ 见表 1.

表 1 沉积物标样中各元素的盐酸提取量与总量

Tab. 1 Total contents and the $\mathrm{HCl}$ extractable contents of the analyzed elements in geochemical certificated sediments.

\begin{tabular}{lccccccccc}
\hline & $\begin{array}{c}\mathrm{Ca} \\
(\mathrm{g} / \mathrm{kg})\end{array}$ & $\begin{array}{c}\mathrm{Fe} \\
(\mathrm{g} / \mathrm{kg})\end{array}$ & $\begin{array}{c}\mathrm{Mn} \\
(\mathrm{g} / \mathrm{kg})\end{array}$ & $\begin{array}{c}\mathrm{Cd} \\
(\mathrm{mg} / \mathrm{kg})\end{array}$ & $\begin{array}{c}\mathrm{Cr} \\
(\mathrm{mg} / \mathrm{kg})\end{array}$ & $\begin{array}{c}\mathrm{Cu} \\
(\mathrm{mg} / \mathrm{kg})\end{array}$ & $\begin{array}{c}\mathrm{Ni} \\
(\mathrm{mg} / \mathrm{kg})\end{array}$ & $\begin{array}{c}\mathrm{Pb} \\
(\mathrm{mg} / \mathrm{kg})\end{array}$ & $\begin{array}{c}\mathrm{Zn} \\
(\mathrm{mg} / \mathrm{kg})\end{array}$ \\
\hline $\mathrm{GSD}_{\mathrm{Std}}$ & $38.2(1.0)$ & $34.0(0.8)$ & $0.62(0.03)$ & $0.26(0.05)$ & $85(10)$ & $32(3)$ & $32(4)$ & $23(4)$ & $78(5)$ \\
$\mathrm{GSD}_{\mathrm{HCl}}$ & $31.4(0.2)$ & $9.6(3.0)$ & $0.33(0.03)$ & $0.45(0.09)$ & $10(3)$ & $14(3)$ & $12(3)$ & $11(0.4)$ & $44(7)$ \\
$\mathrm{E}_{\mathrm{HCl}} / \mathrm{E}_{\mathrm{Std}}$ & 0.82 & 0.28 & 0.53 & $\underline{1.73}$ & 0.12 & 0.44 & 0.38 & 0.48 & 0.56 \\
$\mathrm{GSD} 12_{\mathrm{Std}}$ & $8.3(1.2)$ & $34.2(0.9)$ & $1.4(0.07)$ & $4.0(0.4)$ & $35(4)$ & $1230(51) 12.8(1.9) 285(16)$ & $498(27)$ \\
$\mathrm{GSD} 12_{\mathrm{HCl}}$ & $3.9(0.2)$ & $7.6(0.7)$ & $0.73(0.02)$ & $3.3(0.03)$ & $8(0.1)$ & $938(6)$ & $6.3(0.4)$ & $201(4)$ & $377(9)$ \\
$\mathrm{E}_{\mathrm{HCl}} / \mathrm{E}_{\mathrm{Std}}$ & 0.47 & 0.22 & 0.52 & 0.83 & 0.23 & 0.76 & 0.49 & 0.71 & 0.76 \\
\hline
\end{tabular}

*下标 Std 表示标样提供的总量及其误差,下标 $\mathrm{HCl}$ 表示盐酸可提取含量及其误差;括号中的数据表示标准偏差 (GSD-9 的统计量为 3, GSD-12 的统计量为 4) ; “-”表示未检出.

铬的提取效率较低,主要是因为沉积物中 $\mathrm{Cr}$ 的活性较低所致. GSD-9 的 Cd 因含量过低使得其测定误 差很大 (表 1 ). 其余元素的提取效率基本在 $30 \%$ 以上. 在环境分析中,这种提取效率基本上是可以接受 的,代表了沉积物中大部分的生物有效态含量, 未被提取出来的残渣部分一般很难重新进人生物地球化学 循环中. 尽管各元素的提取百分比各不相同,但 $\mathrm{E}_{\mathrm{HCl}}$ 的提取比例还是比较稳定的,标准偏差一般都大大小 
于其含量. 相比较而言, GSD-9 由于污染很轻, 重金属含量很低, 其相对误差明显高于 GSD-12, 相对误差最 高的是 $\mathrm{Cr}$, 达 30\%, 其次是 $\mathrm{Ni}$, 达 25\%, Cu 的相对误差 21\% (表 1). 其余元素则都在 20\% 以内 (表 1 ). GSD-12 中, 所有元素的相对误差均在 10\% 以内 (表 1). 沉积物重金属的微量分析, 这一误差也是基本可以 接受.

\section{3 沉积物中重金属的垂向分布}

梅梁湾、夹浦、胥口湾三个沉积物柱状样品中沉积物容重、沉积速率、烧失量及各元素含量的垂向分布 见图 3. 需要说明的是, 沉积年代是根据 ${ }^{210} \mathrm{~Pb} 、{ }^{137} \mathrm{Cs}$ 分析结果推断的参考年代,而并非精确年代.

根据各指标的垂向分布特征, 梅梁湾的沉积物重金属累积大致可以分为四个时段 (图 3). $1920-1940$ 年,除 $\mathrm{Cu}$ 出现一个单点峰值外,多数元素的累积速率比较平稳, 沉积物的质量沉积速率也比较平稳. 这反 映出该时段太湖流域人类活动比较缓和. 个别层位 $\mathrm{Cu}$ 出现峰值, 很可能是由于偶然因素引起的增高, 如船 舶丢弃物等偶然事件所致,不可能是整个水域水体含量出现如此大的波动所致.

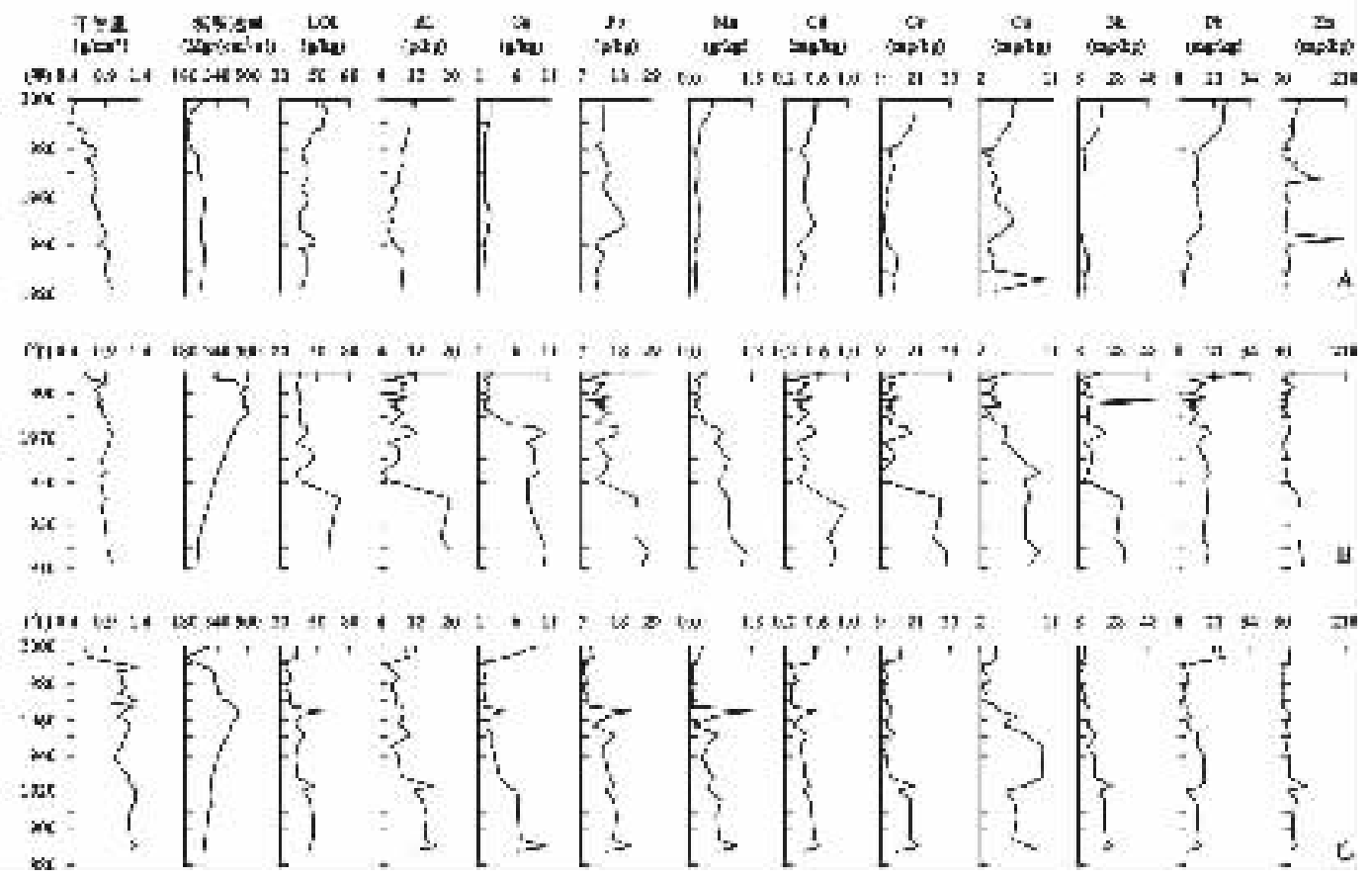

图 3 梅梁湾 $(\mathrm{A})$ 、夹浦 $(\mathrm{B})$ 、胥口湾 $(\mathrm{C})$ 沉积物中容重、沉积速率、烧失量及元素含量的垂向分布

Fig. 3 Vertical distribution of bulk density, sedimentation rate, loss on ignition and the elements in three sediment cores.

$1940-1959$ 年, 沉积物中 $\mathrm{Pb} 、 \mathrm{Cu} 、 \mathrm{Cd}$ 等重金属均出现一个明显的累积峰值, 说明该时段梅梁湾已经受 到流域重金属的污染. 这很可能是该时段无锡市工业的发展所致. 建国以前无锡市的工业主要涉及面粉、 纺织和机械工业,工业已经颇具规模. Fe、Mn 含量的峰值与重金属含量峰值一致. 自 1959 年至 1978 年间, 对大部分重金属来说都是一个低累积速率时期. 只有 Zn 出现了一个峰值. 而自 1978 年至 2000 年, 所有重 金属元素都呈现逐渐增加的趋势. 这一现象与 20 世纪 80 年代以来, 无锡、常州等太湖北部湖区的主要污 水来源区的工农业迅速发展及梅梁湾水质的不断恶化的趋势一致. 与之相对应的是, 沉积物 LOI 和 P 含量 也表现出同样的趋势, 而 $\mathrm{Fe}$ 的增加趋势并不明显. 这说明梅梁湾近二十多年来的重金属污染与水体的有 机污染是同步进行的.

夹浦沉积物中重金属的垂向分布则比梅梁湾的要复杂得多. 从图 3 可以看出, 该湖区重金属的累积大 体上可以分为 6 个时段: 1942 年以前, 绝大多数重金属的含量都很高, 几乎是沉积物柱中含量最高的一段. 
与之对应的是, 该时段沉积物中有机质、铝、钻、铁、锰的含量也几乎是最高的,与重金属的变化非常一致. 这说明,1943 年以前的沉积物地球化学性质与后期沉积的差异很大,其中有机质和铁、铝、锰等粘土矿物、 碳酸钙等的含量都比现在要高, 同时也富集了重金属. 对比该时段的沉积物资料沉积速率发现, 该时段沉 积物的沉积速率明显低于后期, 推测在 1943 年以前, 太湖上游流域的植被比较好, 粗颗粒的泥沙输人量较 少, 沉积物的沉积速率较低, 而且含有更高比例的粘土矿物及有机质, 他们富集了更多的重金属. 与夹浦水 质特征相似的小梅口采集的沉积物的粒度垂向分布 (图 4), 也证实了这种推测. 下层沉积物的粒度明显比 较细. $1943-1952$ 年, 是一个突变期, 各元素的含量迅速下降. $1952-1967$ 年, 各指标都出现了一个小峰, 元素的峰值与有机质 ( LOI) 峰值明显相关.

$1967-1977$ 年, 各元素出现了一个更为明显的峰值. 这一峰值与 $\mathrm{Ca} 、 \mathrm{Fe}$ 等的峰值非常一致, 而有机质 的变化不大, 这说明该峰值的出现与沉积物矿物性质的变化相关. 1977 年到 1997 年的 20 年间, 沉积物中 各元素的含量都是剧烈变化, 但总体含量都比较低. 同一时段沉积物有机质的含量始终很低, 该时段沉积 物的质量沉积通量却处于最大时期. 结合图 4 的粒度变化规律可以推测,该时段主要沉积了大量粗颗粒矿 物, 由于粒度较粗, 粘土矿物比例相对较少, 使得该时段总体重金属元素的含量偏低, 同时粒度较粗也造成 了沉积物化学成分间的不均匀, 引起该时段沉积物中金属元素含量变化剧烈. 1997-2000 年的表层沉积物 中各元素的含量则再次出现峰值. 从沉积物的干容重看, 表层沉积物的干容重明显偏低, 说明表层沉积物的 含水率较高. 而元素含量较高可能是由于表层沉积物是一层含水率高、粒度较细的悬浮沉积物.

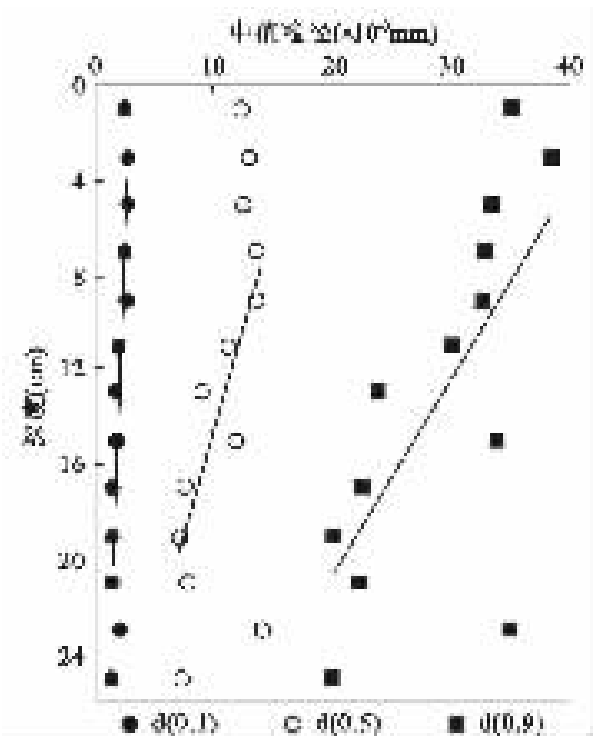

图 4 太湖小梅口湖区沉积物中值粒径的垂向分布

Fig. 4 Vertical distribution of mean value of grain size of sediment in Xiaomeikou area, Lake Taihu. $\mathrm{d}(0.1) 、 \mathrm{~d}(0.5) 、 \mathrm{~d}(0.9)$ 代表粒度积分曲线中 自小到大积分 $10 \% 、 50 \% 、 90 \%$ 时达到的粒径

除表层 $3 \mathrm{~cm}$ 外, 胥口湾沉积物中各元素及有机质含量 都是由底层至表层总体下降. 金属元素的累积也大致可以 分为 5 个时段 (图 3):1887-1920 年略有下降趋势; 19201957 年多数元素变化仍比较平缓, 但 $\mathrm{Cu} 、 \mathrm{~Pb}$ 则出现一个明 显的峰值, 沉积物质量沉积通量也线性增加; $1957-1967$ 年 沉积物质量沉积通量达到最大, 沉积速率是 1920 年以前的 一倍多, 沉积物中有机质含量、 $\mathrm{Fe} 、 \mathrm{Mn}$ 含量出现一个短期峰 值, 沉积物中 Cd 的含量也出现一个峰值, 反映出期间该湖 区人类活动非常剧烈; $1967-1990$ 年各元素含量及沉积物 有机质含量都比较低,年际变化平缓; $1990-2000$ 年沉积物 的沉积速率、含水率急剧下降, 各元素的含量则明显增加, 这种现象与夹浦的表层富集现象一致.

比较三个湖区沉积物的干容重和含水率(图 3), 可以明 显地看出, 梅梁湾沉积物中沉积物的干容重较小, 且由表层 至底层 $28 \mathrm{~cm}$ 处沉积物的干容重逐渐增大, 表层约 $10 \mathrm{~cm}$ (1978 年以来) 沉积物的干容重小于 1 , 反映出梅梁湾沉积 物中含水率和有机质含量较高, 比较松软, 在风浪的作用下 也容易被再悬浮起来. 而正向草型化发展的胥口湾沉积物 的干容重很大,除表层 $3 \mathrm{~cm}$ 外,下层沉积物的干容重基本都 在 1.2 以上,而且近百年的变化不大. 就沉积速率而言, 梅梁 湾的沉积速率一直处于较低水平, 而夹浦和胥口湾则分别 在 1985 和 1963 年前后达到一个峰值, 峰值的强度可以超过梅梁湾 1 倍以上. 说明相对于夹浦和胥口湾而 言, 梅梁湾的泥沙输人量始终比较低.

\section{3 讨论}

目前我国尚缺乏沉积物中重金属的污染评价标准,但可以参照土壤环境质量标准 $(\mathrm{GB} 15618-1995)$, 以及太湖周围土壤中重金属的自然背景值 ${ }^{[1]}$,对三个沉积物柱状样中的重金属含量进行评价. 从表 2 可以 看出, 与土壤标准相比, 污染最严重的是 $\mathrm{Cd}$. 沉积物中 $\mathrm{Cd}$ 的平均值均高于土壤标准中的一级标准限制值, 
但都低于二级标准. 沉积物中 $\mathrm{Cu}$ 的含量明显低于太湖流域土壤自然本底值, 与袁旭音等人的研究结果一 致 ${ }^{[3]}$, 即由流域土壤到湖泊沉积物, $\mathrm{Cu}$ 的含量呈下降趋势. 沉积物中 $\mathrm{Cu}$ 含量也均低于土壤环境质量标准 中的一级标准, 说明调查区域不存在 $\mathrm{Cu}$ 的污染. $\mathrm{Pb}$ 的平均值都低于一级标准. $\mathrm{Zn} 、 \mathrm{Cr}$ 的平均值低于一级 标准, 夹浦沉积物中的 $\mathrm{Ni}$ 高于一级标准, 但低于二级标准. 总的来说, 从三个沉积物柱状样中的重金属含 量看, 太湖的沉积物重金属污染比较轻微. 然而, 从图 4 可知, 不同年代沉积的沉积物中重金属的含量差异 很大, 其差异甚至大于三个样点沉积物间的差异. 比如三个样点 $\mathrm{Cd}$ 平均值之间的最大差值为 $0.07 \mathrm{mg} / \mathrm{kg}$, 而梅梁湾、夹浦、胥口湾沉积物柱中 $\mathrm{Cd}$ 含量平均值与最大值之间的差值分别为 $0.10 \mathrm{mg} / \mathrm{kg} 、 0.36 \mathrm{mg} / \mathrm{kg}$ 、 $0.18 \mathrm{mg} / \mathrm{kg}$, 均超过了样点平均值之差, 其余元素也有类似规律. 这种现象造成了不同年代的太湖沉积物 重金属污染评价结果之间不一致. 比如张于平等人、王海等人、袁旭音等人分布在 2000 年采样评价太湖沉 积物重金属污染时均发现发现, 北部湖区的 Cd 污染明显比其他湖区严重 ${ }^{[2,6,7]}$. 80 年代的评价结果表 明 ${ }^{[2]}$, 北部梅梁湾沉积物并未发生 Cd 污染, 而是在胥口湾、东太湖等靠近苏州的湖区沉积物 Cd 含量较高. 这充分说明,梅梁湾的重金属污染主要是上世纪 80 年代以后的近 20 年来发生的. 图 3 中梅梁湾沉积物中 重金属垂向分布也表明 1978 年开始,梅梁湾沉积物中重金属含量开始不断增加.

表 2 沉积物中重金属含量与背景值及环境标准的比较

Tab. 2 Comparison between heavy-metal contents in the sediments and the background values, and the environmental quality standard.

\begin{tabular}{cccccccc}
\hline & & $\begin{array}{c}\mathrm{Cd} \\
(\mathrm{mg} / \mathrm{kg})\end{array}$ & $\begin{array}{c}\mathrm{Cr} \\
(\mathrm{mg} / \mathrm{kg})\end{array}$ & $\begin{array}{c}\mathrm{Cu} \\
(\mathrm{mg} / \mathrm{kg})\end{array}$ & $\begin{array}{c}\mathrm{Ni} \\
(\mathrm{mg} / \mathrm{kg})\end{array}$ & $\begin{array}{c}\mathrm{Pb} \\
(\mathrm{mg} / \mathrm{kg})\end{array}$ & $\begin{array}{c}\mathrm{Zn} \\
(\mathrm{mg} / \mathrm{kg})\end{array}$ \\
\hline \multirow{2}{*}{ 最大值 $^{(1)}$} & 梅梁湾 & 0.48 & 128 & 17 & 51 & 44 & 304 \\
& 夹浦 & 0.77 & 193 & 15 & 77 & 33 & 133 \\
& 胥口湾 & 0.52 & 134 & 17 & 63 & 42 & 150 \\
\hline \multirow{2}{*}{ 平均值 $^{(2)}$} & 梅梁湾 $^{*}$ & 0.38 & 85 & 8 & 29 & 27 & 94 \\
& 夹浦 & 0.41 & 97 & 9 & 44 & 28 & 79 \\
土壤自然本底值 $^{(2)}$ & 胥口湾 & 0.34 & 80 & 9 & 34 & 22 & 73 \\
\hline \multirow{2}{*}{ 土壤标准 $^{(3)}$} & 太湖流域 & - & $79.3 \pm 16.2$ & $18.87 \pm 7.53$ & $19.45 \pm 5.31$ & - & $59.15 \pm 13.52$ \\
\hline
\end{tabular}

(1)实际测定值除以按照 GSD -9 和 GSD - 12 分析中的该元素平均提取率.

(2)引自文献 [1].

(3) 一级标准: 为保护区域自然生态, 维持自然背景的土壤环境质量的限制值; 二级标准: 为保障农业生产, 维护人体 健康的土壤限制值, 其中根据土壤的 $\mathrm{pH}$ 高低分为三种, 表中所列为 $\mathrm{pH6} .5-7.5$ (太湖沉积物 $\mathrm{pH}$ 一般在 7.1 以上 $^{[2]}$ ).

致谢: 季江高级工程师协助了野外采样, 夏威岗高级工程师进行了 ${ }^{210} \mathrm{~Pb} 、{ }^{137} \mathrm{Cs}$ 年代测定, 朱育新副研究员进 行了重金属的测定, 东华理工学院王达成、张渠、崔芳兰、黎毓婷、李强参与了样品采集，特此致谢! 


\section{4 参考文献}

[1] 上海师院环境保护研究室, 江苏省无锡市环境保护局. 太湖环境质量调查研究. 上海师范学院学报 (自然科学版环 境保护专辑) ,1983: $95-115$.

[2] 孙顺才, 黄渏平 主编. 太湖. 北京: 海洋出版社, 1993: 219-244.

[3] 袁旭音, 陈 骏, 季峻峰等. 太湖沉积物和湖岸土壤的污染元素特征及环境变化效应. 沉积学报, 2002, 20 (3): $427-434$.

４4］范成新, 朱育新, 吉志军等. 太湖宜溧河水系沉积物的重金属污染特征. 湖泊科学, 2002, 14(3): $235-241$.

[5] 戴秀丽, 孙 成. 太湖沉积物中重金属污染状况及分布特征探讨. 上海环境科学, 2001, 20(2): $71-74$.

６］＼cjkstart王 海, 王春霞, 王子健. 太湖表层沉积物中重金属的形态分析. 环境化学, 2002, 21(5) : 430-435.

[7] 张于平, 翟文川.太湖沉积物中重金属的测定及环境意义. 岩矿测试, 2001, 20(1) : 34 - 36.

[8］石浚哲, 刘光玉. 太湖沉积物重金属污染及生态风险性评价. 环境监测管理与技术, 2001, 13(3): $24-26$.

[9］范成新，刘元波，陈荷生. 太湖底泥蓄积量估算及分布特征探讨. 上海环境科学, 2000, 19(2) : $72-75$.

[10] 刘恩峰, 沈 吉, 朱育新等. 太湖表层沉积物重金属元素的来源分析. 湖泊科学, 2004, 16(2): 113-119.

[11] 郑 一, 王学军, 江耀慈等, 环太湖河道水质分析与人湖污染物负荷量估算. 地理学与国土研究, 2001, 17(1): 40 -44 .

[12] Wetzez R G. Limnology: Lake and River Ecosystems. Third Edition. San Diego:Academic Press, 2001: 625 - 627.

[13] 张运林, 秦伯强, 陈伟民等. 太湖水体中悬浮物研究. 长江流域资源与环境, 2004, 13(3): $266-271$.

[14] Dokulil M, Chen W, Cai Q. Anthropogenic impacts to large lakes in China: the Tai Hu example. Aquatic Ecosystem Health and Management, 2000, 3: 81 -94.

[15] 杨清心. 东太湖水生植被的生态功能及调节机制. 湖泊科学, 1998, 10(1) : 67-72.

[16] 李文朝. 东太湖荠黄水发生原因与防治对策探讨. 湖泊科学, 1997, 9(4) : $364-368$.

[17] Qin BQ. Hydrodynamics of Lake Taihu, China. Ambio, 1999, 28(8) : $669-673$.

[18] 秦伯强, 胡维平, 陈伟民等. 太湖梅梁湾水动力及相关过程的研究. 湖泊科学, 2000, 12(4): $327-335$.

[19] 逢 勇, 兴培民. 太湖风生流三维数值模拟试验. 地理学报, 1996, 51(4) : 322 - 328.

[20] Sondergaard M, Windolf J, Jeppesen E. Phosphorus fractions and profiles in the sediment of shallow Danish lakes as related to phosphorus load, sediment composition and lake chemistry. Water Research, 1996, 30(4) : $992-1002$.

[21 ] 中国环境监测总站. 土壤元素的近代分析法. 北京: 中国环境科学出版社, 1992: 69-70. 